\title{
Crosslinked ionomer gel separators for polysulfide shuttle mitigation in magnesium-sulfur batteries: Elucidation of structure-property relationships
}

Hunter O. Ford, Laura C. Merrill, Peng He, Sunil P. Upadhyay, Jennifer L. Schaefer*

Department of Chemical and Biomolecular Engineering, University of Notre Dame, Notre Dame, IN 46556, USA

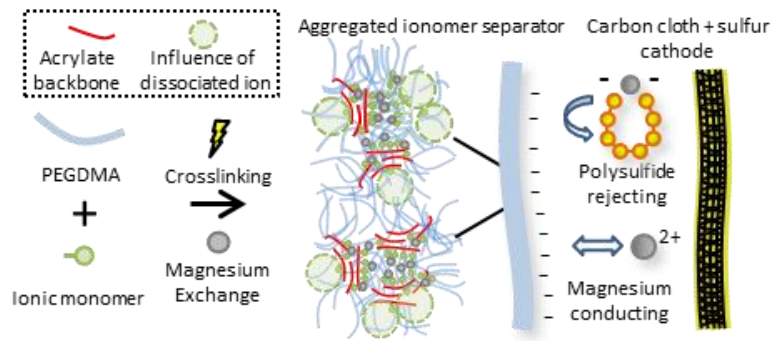

Table of Contents Image

\begin{abstract}
A series of crosslinked ionomer networks of varying poly(ethylene glycol) diacrylate crosslinker chain length, ionic co-monomer chemistry, and co-monomer ratio have been studied for their use as polysulfide shuttle inhibiting separators in magnesium-sulfur $(\mathrm{Mg}-\mathrm{S})$ batteries. Through the use of X-ray scattering, polysulfide diffusion experiments, conductivity measurements, and Mg$\mathrm{S}$ cell cycling, it was determined that inclusion of tethered anions in polymer networks mitigates the polysulfide shuttle effect. Polysulfide crossover through networks into a bulk electrolyte can be reduced by absorption into the polymer gel, steric rejection, and electrostatic rejection, with the predominance of these mechanisms dictated by polymer composition and structure. The best network composition allowed an initial Mg-S cell discharge capacity of $522 \mathrm{mAh} / \mathrm{g}$ compared to a discharge capacity of $365 \mathrm{mAh} / \mathrm{g}$ using a literature standard glass fiber separator. The ionomer cell saw $67 \%$ capacity retention after three cycles, whereas the glass fiber separator could not complete the first charging cycle due to polysulfide shuttle.
\end{abstract}

\section{Introduction}

To meet the energy storage needs of the future, the development of a wide array of rechargeable battery chemistries is of paramount importance. Of specific interest are systems capable of delivering high energy density safely and at practical cost, thereby enabling the electrification of transportation. Fully electric transportation, coupled with a rise in sustainable energy generation, will help to mitigate the effects of climate change via a reduction in fossil fuel usage. One such high-energy dense system is the magnesium sulfur $(\mathrm{Mg}-\mathrm{S})$ battery, offering a high theoretical volumetric energy capacity of $3200 \mathrm{Wh} / \mathrm{L}$. In addition magnesium and sulfur are both abundant and low-cost materials, making them an ideal choice for a sustainable battery technology.

Like all metal-sulfur batteries, the Mg-S system suffers from a phenomenon known as the polysulfide shuttle effect. During the operation of the Mg-S system, intermediate species, magnesium polysulfides (MgPS), are generated and consumed in the sulfur cathode. MgPS can diffuse away from the cathode, and during the charging process become reduced at the 
magnesium metal anode, either irreversibly adhering to the surface or returning to the cathode to repeat the redox shuttle. This process leads to the formation of a passivating layer, loss of active material, and poor cycle efficiency. ${ }^{1}$ The polysulfide shuttle effect results in dramatic capacity fading and short life-times of the Mg-S cell, precluding the practical use of this battery system.

Since the demonstration of the first Mg-S cell, much attention has been focused on mitigating the polysulfide shuttle effect to prolong cell capacity. Sulfur has been incorporated into high surface area graphene, ${ }^{2}$ mesoporous carbon structures, ${ }^{3}$ carbon nanofiber (CNF) interlayer cathodes, ${ }^{4}$ and graphidiyne cages. ${ }^{5}$ In addition, it has been shown that the polysulfide effect can be lessened by reducing the solubility of polysulfides and sulfur in the electrolyte by increasing the electrolyte salt concentration. ${ }^{6}$ While these approaches have been successful, it is desirable to explore additional means of further mitigating the polysulfide shuttle effect to allow practical use of $\mathrm{Mg}$ $\mathrm{S}$ cells.

In the Li-S literature, reported attempts to mitigate the polysulfide shuttle effect are numerous; strategies involving polymers include encapsulation of sulfur particles with conductive polymers, the use of specialty cathode binders, and application of ionomers with electrostatic polysulfide rejection mechanisms. ${ }^{7-14}$ The use of polymeric coatings on sulfur cathodes and separators has dramatically improved performance in Li-S cells, yet none have eliminated the presence of polysulfides in the electrolyte. Notably, there has been limited study of correlations between the structure of sulfur cathode polymeric functional layers and polysulfide transport.

Herein we report on a class of polymers capable of impacting and mitigating the polysulfide shuttle effect in $\mathrm{Mg}$-S cells. The polymers are crosslinked ionomeric networks that effectively repel polysulfides via physical and electrostatic mechanisms. Polyethylene glycol diacrylate or dimethacrylate (PEGDA/PEGDMA) is copolymerized with an ionic monomer, resulting in a crosslinked network of tethered anionic groups bridged by PEG linkers. When swelled in an electrolyte, some degree of the ionic groups undergo dissociation. The resultant network consisting of tethered negative charges is hypothesized to facilitate cationic conduction while also minimizing the polysulfide shuttle effect due to electrostatic exclusion of the negatively charged polysulfide anions.

An effort to understand the fundamentals governing ion transport in these systems has been made, in the hopes that such an understanding will lead to the engineering of better materials for $\mathrm{Mg}-\mathrm{S}$ and other metal sulfur systems. The effects of PEG linker length, tethered anion chemistry, and charge:ether oxygen ratio (Ch:EO) on ion transport and material structure are investigated. Conductivity measurements, small angle x-ray scattering (SAXS) analyses, polysulfide diffusion experiments, and cell cycling tests have been employed to provide a comprehensive picture of structure-composition-property relationships. It is found that with an increase in bound charge content (Ch:EO), the electrolyte swelled networks become less conductive to cationic species but also more greatly restrict polysulfide transport. The rejection of polysulfide species is shown to be a result of two distinct mechanisms, electrostatic repulsion and physical restriction, with the best performing films taking advantage of both mechanisms while balancing cationic conductivity. A series of $\mathrm{Mg}-\mathrm{S}$ cells with ionomer separators exhibit a variety of discharge capacities and capacity retention as a function of film composition. 


\section{Experimental Section}

Preparation of self-supporting films:

Poly(ethylene glycol) diacrylate (PEGDA) $\left(M_{n}=700 \mathrm{~g} / \mathrm{mol}\right)$ (Sigma-Aldrich) is washed first with n-hexanes (Sigma-Aldrich) then pentane (Sigma-Aldrich) to remove stabilizers. Poly(ethylene glycol) dimethacrylate (PEGDMA) $\left(M_{n}=1000 \mathrm{~g} / \mathrm{mol}\right)$ (Polysciences, Inc) is used as received. Ionic monomer sodium 4-vinylbenzenesulfonate (NaSS) (> $90 \%$ technical, SigmaAldrich) is used as received, and ionic monomer potassium 4-styrenesulfonyl (trifluoromethylsulfonyl)imide (KSTFSI) is synthesized according to Armand et. al. ${ }^{15}$ Magnesium metal is purchased from Gallium Source. Structures for PEGDA, PEGDMA, NaSS, and KSTFSI are presented in Figure 1 a-d.

(a)

(b)<smiles>C=CC(=O)OCCOC(=O)C=CC(=O)OCCOC(=O)C(=C)C</smiles>

Figure 1. Monomers used in ionomer fabrication (a) PEGDA (b) PEGDMA, (c) NaSS, (d) KSTFSI.

In ambient conditions, the PEGDA/PEGDMA monomer of a given chain length and a given ionic monomer are dissolved in dimethyl sulfoxide (DMSO) (Sigma-Aldrich). Photoinitiator 2hydroxy-4'-(2-hydroxyethoxy)-2-methyl propiophenone (Sigma-Aldrich) is added to the solution which is then stirred. The solution of monomers, photo-initiator, and DMSO is then sandwiched between two 1/4" thick borosilicate glass plates (McMaster Carr) separated by $200 \mu \mathrm{m}$ thick glass microscope slides (VWR), which are placed in a UVC-515 Ultraviolet Multilinker $254 \mathrm{~nm}$ UV oven. The films are photo-crosslinked for a total of 45 minutes. The resultant polymers are washed with $18 \mathrm{M} \Omega$ deionized water to remove unreacted material. The films are then placed in a stirred aqueous ion exchange solution of $0.5 \mathrm{M}$ magnesium chloride to achieve magnesiated forms of the polymer. The ion exchange solution is replaced every 12 hours for 48 hours, after which free salt is washed from the films by repeating the same process but with pure deionized water. The films are air dried, brought into an argon filled glovebox, and vacuum dried for 24 hours at $80{ }^{\circ} \mathrm{C}$ to remove residual moisture. Ion exchange is confirmed via inductively coupled plasma-optical emission spectroscopy (ICP-OES).

Samples are referenced by the PEGDA/PEGDMA monomer with the number of repeat units, followed by the ionic monomer denotation, then the Ch:EO ratio. For example, a PEGDA with $M_{n}=700 \mathrm{~g} / \mathrm{mol}$ STFSI film of $\mathrm{Ch}: \mathrm{EO}=0.007$ would be referenced as PEG $_{13}$ DA_x_STFSIMg_7.

\section{Conductivity Measurements}

Conductivity was measured on samples of swelled polymer films sandwiched between brass electrodes with a Novocontrol Turnkey Broadband Dielectric Spectrometer. Samples are swelled to equilibrium and then secured into the sample cell while in the glovebox.

\section{Ultra-Dry solvent preparation}

All solvents used in electrochemical tests, H-cell experiments, and UV/Vis experiments are dried to less than $10 \mathrm{ppm}$ moisture as confirmed by Karl Fischer titration. For tetrahydrofuran (THF, anhydrous, Sigma-Aldrich) this is achieved by storing over $3 \AA$ A molecular sieves. For 1,2- 
dimethoxyethane (DME, 99.5\% anhydrous, Sigma-Aldrich) this is achieved by distillation over calcium hydride then storage on molecular sieves.

\section{H-Type Diffusion Experiments}

A section of polymer film to be tested is allowed to swell in anhydrous THF. The swelled film is then placed between the two halves of the H-cell. To one side of the H-cell, $3 \mathrm{~mL}$ of a magnesium polysulfide solution is added, while simultaneously $3 \mathrm{~mL}$ of neat electrolyte is added to the opposite side. The cell is left for 24 hours, after which the solution on the side into which MgPS diffuse is collected and analyzed via UV/Vis spectroscopy. The H-cell electrolyte is prepared according to literature. ${ }^{16}$ A solution of molar ratio 1:4 magnesium bis(hexamethyldisilazide) $\left(\mathrm{Mg}(\mathrm{HMDS})_{2}\right) \quad(>97 \%$, Sigma-Aldrich) to magnesium chloride $\left(\mathrm{MgCl}_{2}\right)$ (>99.9\%, anhydrous, Aldrich), $0.5 \mathrm{M}$ with respect to total magnesium content, is created by dissolving $\mathrm{Mg}(\mathrm{HMDS})_{2}$ in anhydrous THF and then adding $\mathrm{MgCl}_{2}$ and allowing to equilibrate. Magnesium polysulfide solutions are prepared by adding $0.0144 \mathrm{~g}$ elemental sulfur (Aldrich) to $3 \mathrm{~mL}$ of the aforementioned $\mathrm{Mg}(\mathrm{HMDS})_{2}-\mathrm{MgCl}_{2}$ electrolyte solution and stirring. The solution color quickly changes from pale yellow, to light blue, to a deep yellow after two hours of equilibration. It is then used in the H-cell. Eventually, continued reaction yields a white precipitate, however the MgPS solutions are stable long enough to be used in the 24 hour H-cell experiment, with precipitate only being formed after a few days of solution equilibration.

\section{Small/wide angle $x-$ ray scattering (SAXS/WAXS)}

Polymer samples are loaded into capillary tubes in an argon filled glovebox then swelled with solvent. The tubes are sealed within the glovebox to prevent solvent evaporation and incorporation of moisture into the polymer sample. SAXS/WAXS measurements were obtained using the Argonne APS synchrotron beamline 12-ID-B, operated by the Chemical and Materials Science group at Argonne National Laboratory, with an X-Ray beam wavelength of $0.9322 \AA$ (energy of $13.3 \mathrm{keV}$ ).

\section{Ultraviolet/Visible (UV/Vis) Spectroscopy}

Samples were prepared in 10x1 mm quartz micro-cuvettes (Type 46 Firefly Sciences) in an argon filled glovebox. The cuvette is sealed, and then measured using a Jasco V-670 UVVisible-Near IR Spectrometer, from $212 \mathrm{~nm}$ (cutoff wavelength for THF) to $650 \mathrm{~nm}$.

\section{Cathode Preparation and cell cycling}

A $0.35 \mathrm{M}$ (with respect to $\mathrm{Mg}$ ) THF based electrolyte containing 1:2 $\mathrm{Mg}(\mathrm{HMDS})_{2}: \mathrm{AlCl}_{3}$ is prepared according to literature. ${ }^{17}$ Likewise, a $0.25 \mathrm{M}$ (with respect to $\mathrm{Mg}(\mathrm{TFSI})_{2}$ ) DME based electrolyte containing 1:2 $\mathrm{Mg}(\mathrm{TFSI})_{2}: \mathrm{MgCl}_{2}$ is prepared according to literature and used unconditioned. ${ }^{6}$ Sulfur is incorporated into high surface area activated carbon cloth (ACC) (Ceramaterials FM10) discs, $0.5 \mathrm{~mm}$ thick and $1 \mathrm{~cm}$ in diameter, by two different methods depending on the electrolyte to be used. For the DME based electrolyte, within the glovebox a solution of sulfur dissolved in THF is added to the ACC such that when the THF is evaporated the sulfur loading is $1 \mathrm{mg} / \mathrm{cm}^{2}$. For the THF based electrolyte, inside the glovebox $4 \mathrm{mg}$ of sulfur are spread onto a ACC disc, which is then loaded in a Teflon vessel which is sealed inside a stainless steel reactor. The reactor is then held at $155^{\circ} \mathrm{C}$ for 12 hours. The additional sulfur is required for the THF based electrolytes to prevent complete sulfur dissolution into the large amount of electrolyte needed to fully wet the cathode and separator. Structures for $\operatorname{Mg}(\operatorname{HMDS})_{2}$ and $\mathrm{Mg}(\mathrm{TFSI})_{2}$ are presented in Figure $2 \mathrm{a}-\mathrm{b}$. 


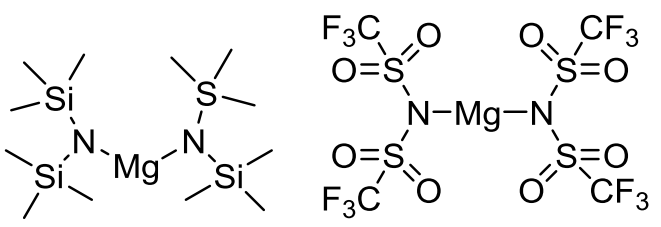

Figure 2. Magnesium electrolyte salts (a) $\operatorname{Mg}(\mathrm{HMDS})_{2}$ (b) $\operatorname{Mg}(\mathrm{TFSI})_{2}$

The cathodes are assembled in coin-type cells with the cathode supported in a teflon donut (to prevent cathode dewetting when cell is crimped), glass fiber (Whatman) or ionomer film as a separator, Mg metal anode with freshly removed oxide layer, $160 \mu \mathrm{L}$ electrolyte, and stainless steel spacers and wave spring. $\mathrm{Mg}$ foil is cleaned via mechanical scraping immediately prior to use. Cells are rested two hours before initial discharge and are tested at a rate of $0.005 \mathrm{C}$ with respect to sulfur on a Neware Battery Tester Systems battery tester.

\section{Results and Discussion}

\section{Structural Determination via Small Angle X-Ray Scattering (SAXS)}

To elucidate the structure-property relationships of this class of ionomer networks, morphology is probed with the use of SAXS. Scattering spectra for THF swelled $P_{E G}{ }_{20}$ DMA and $P G_{13} D A$ ionomers with varying $\mathrm{Ch}: \mathrm{EO}$ and anion chemistry are presented in Figure $3 \mathrm{a}$ and $3 \mathrm{~b}$, respectively. For a given scattering spectra, a local maximum in scattering intensity, $\mathrm{q}_{\mathrm{x}}$, can be used to determine the average distance between the structures responsible for the scattering, $d_{x}$, by means of the Bragg condition, where $\mathrm{q}_{\mathrm{x}}=2 \pi / \mathrm{d}_{\mathrm{x}} \cdot{ }^{18}$ A sharper local maximum indicates a more monodisperse set of length scales that give rise to the observed average length scale. 

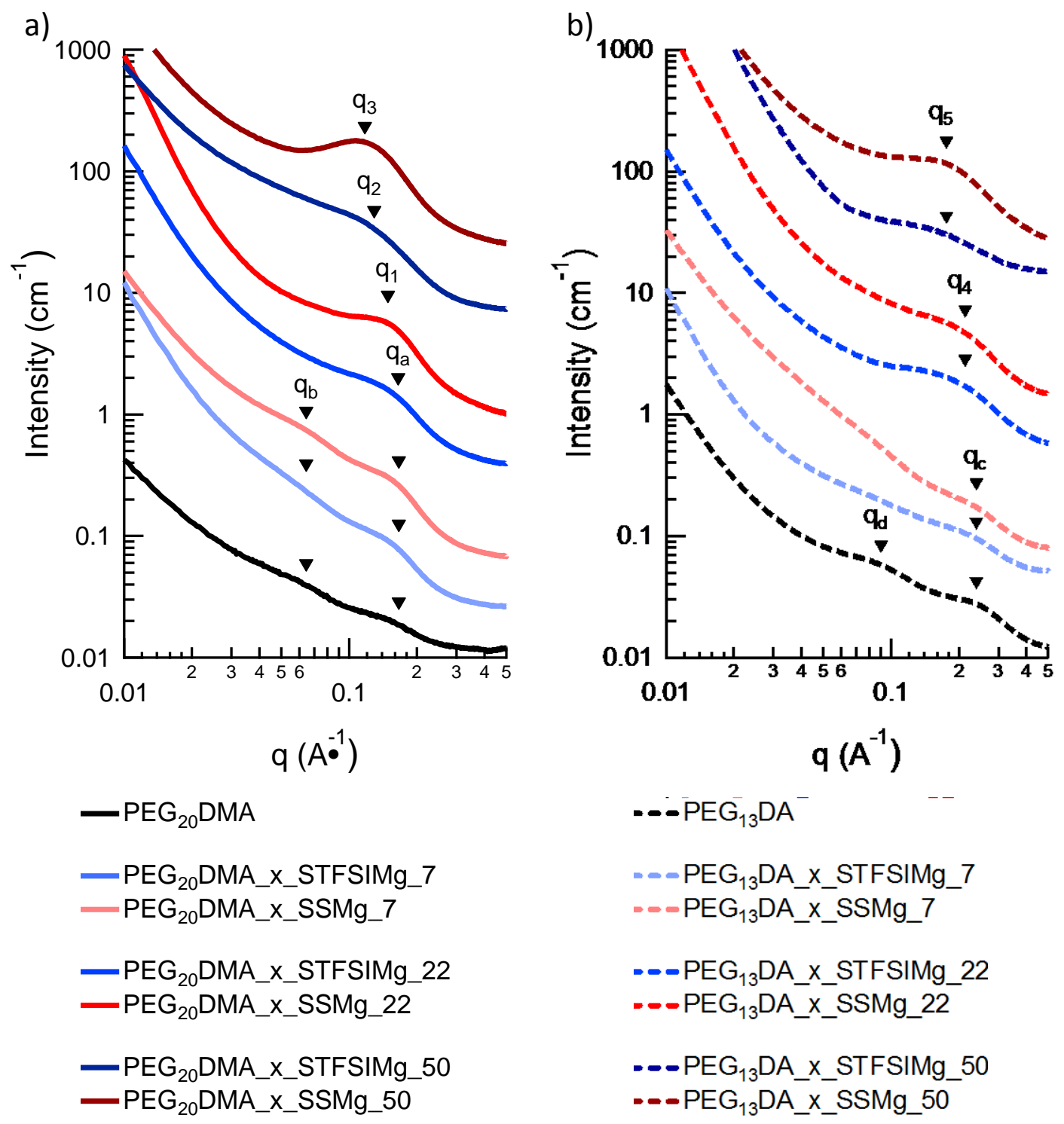

Figure 3. SAXS spectra for $\mathrm{PEG}_{20} \mathrm{DMA}$ (a) and $\mathrm{PEG}_{13} \mathrm{DA}$ (b) ionomers of varying anion chemistry and Ch:EO. Samples are swelled in THF and analyzed at room temperature $\left(23^{\circ} \mathrm{C}\right)$. Spectra are shifted vertically for clarity.

In the case of the pure PEGDA/PEGDMA films, the acrylate backbones segregate, producing acrylate rich and acrylate poor regions. ${ }^{19-21}$ Peaks $\mathrm{q}_{\mathrm{a}}$ and $\mathrm{q}_{\mathrm{c}}$ are assigned to the correlation length between acrylate-rich clusters. Secondary peaks $q_{b}$ and $q_{d}$ are indicative of moderate range order between scattering structures. ${ }^{22}$ Note the characteristic distance between acrylate backbones is shorter in the $\mathrm{PEG}_{13} \mathrm{DA}$ case due to the shorter crosslinker length. By steric necessity, the portion of the PEG chains that are attached to the acrylate backbones are more extended and densely packed compared to the acrylate poor regions where there is substantial chain looping. A schematic of this proposed structure is presented in Figure 4a. Considering the spacing between chains as the pore size, a proportional averaging of the acrylate rich and poor regions constitutes 
an effective pore size. With comparable acrylate domain sizing, the $\mathrm{PEG}_{20} \mathrm{DMA}$ films have a larger portion of acrylate poor region, yielding a larger effective pore size relative to $\mathrm{PEG}_{13} \mathrm{DA}$ films.

In the case of the lowest charge content, $\mathrm{Ch}: \mathrm{EO}=0.007$, ionic units have been incorporated without a measureable change in the material structure as depicted in Figure $4 \mathrm{~b}$, indicating a high degree of dissociation of the ionic units. The tethered dissociated anions create regions influenced by negative charge, the range of which is determined by the Debye length of the swelling solvent and/or electrolyte.

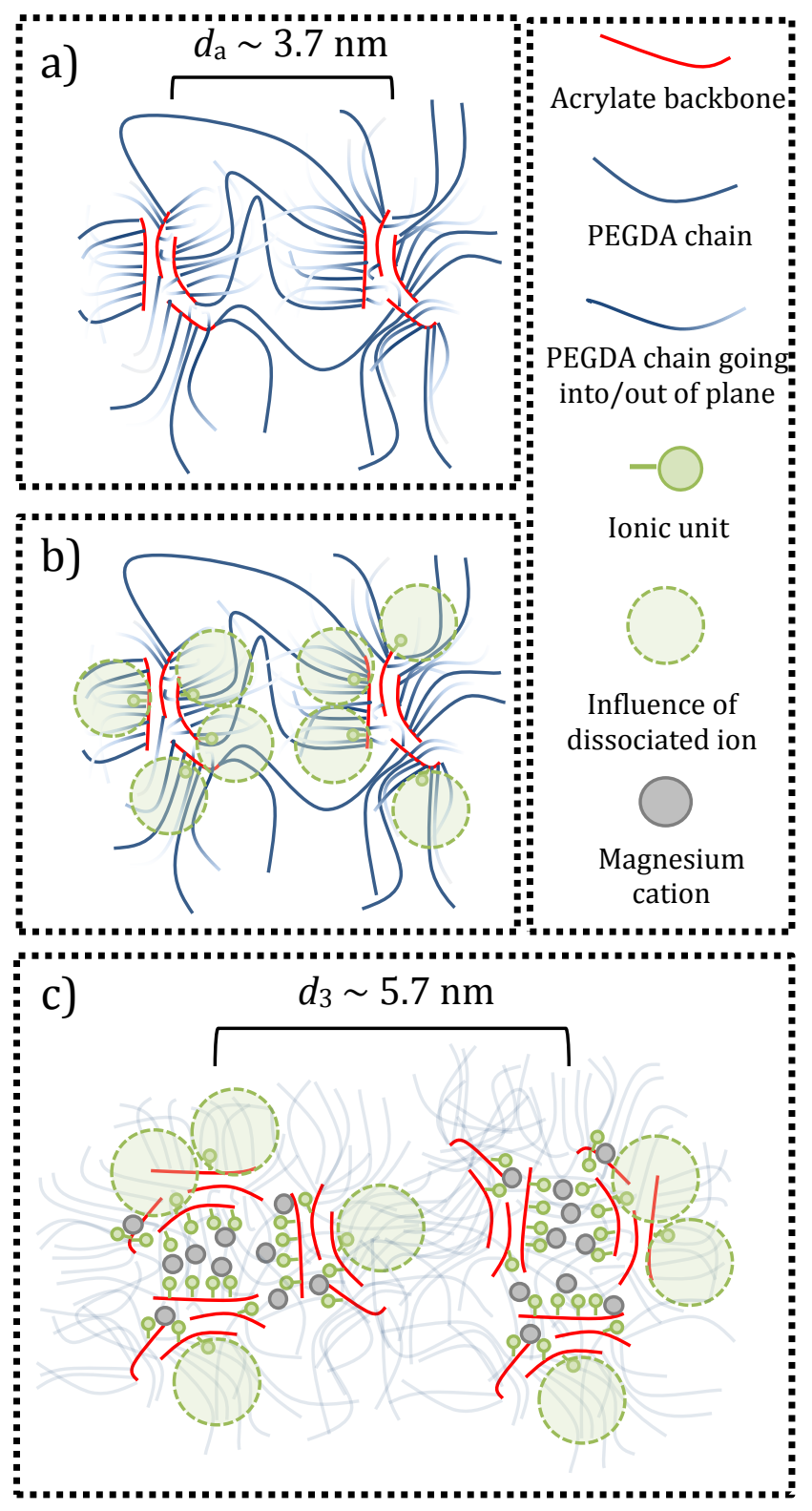

Figure 4. Schematic detailing proposed morphology of a) pure PEGDA/PEGDMA films b) unaggregated films containing ionic units and c) aggregated ionomer films. Pictured as a two 
dimensional representation, chains with a color gradient are going into and out of the plane. For clarity, PEG chains are lightened in box c.

Moderate to high $\mathrm{Ch}: \mathrm{EO}$ ratios result in ionic aggregation as depicted in Figure 4c, indicated by the evolution of the characteristic ionomer peak with increasing Ch:EO (peaks $\mathrm{q}_{1}-\mathrm{q}_{5}$ ) and an increase in distance between scattering structures. ${ }^{23}$ In general, samples with the STFSI anion experience a lower degree of length scale shift and have broader correlation peaks, indicating a lesser degree of aggregation. Due to its electron delocalizing nature the STFSI anion has been shown to have a lower ion pair binding energy relative to the SS anion, ${ }^{24}$ which promotes ion pair dissociation and leads to differences in aggregation degree and transport properties. Further discussion concerning the relationship of ion dissociation and degree of aggregation is found in the SI.

It is likely that the ionic aggregates are surrounded by densely packed PEG sheaths, with the interaggregate distance determined by the size of the aggregate and corresponding polymer shell. $^{25,26}$ The dense packing of PEG chains around the aggregates and the greater extension of any chains bridging between aggregates (due to the larger distance between scattering structures relative to pure the PEGDA/PEGDMA case) leads to a decrease in free volume and therefore effective pore size. Unfortunately, the x-ray scattering length density contrast between PEG chains and THF is not high enough to directly observe pore size. However, the results from the conductivity and MgPS diffusion experiments support the claim that effective pore size decreases with greater aggregation and shorter crosslinker length.

\section{Conductivity}

The conductivity of the ionomers is studied in an effort to understand the compositional impact on cation transport. The DC conductivity values for pure THF swelled PEG $_{20}$ DMA and $\mathrm{PEG}_{13} \mathrm{DA}$ ionomers with varying $\mathrm{Ch}: \mathrm{EO}$ and anion chemistry are presented in Figure 5.

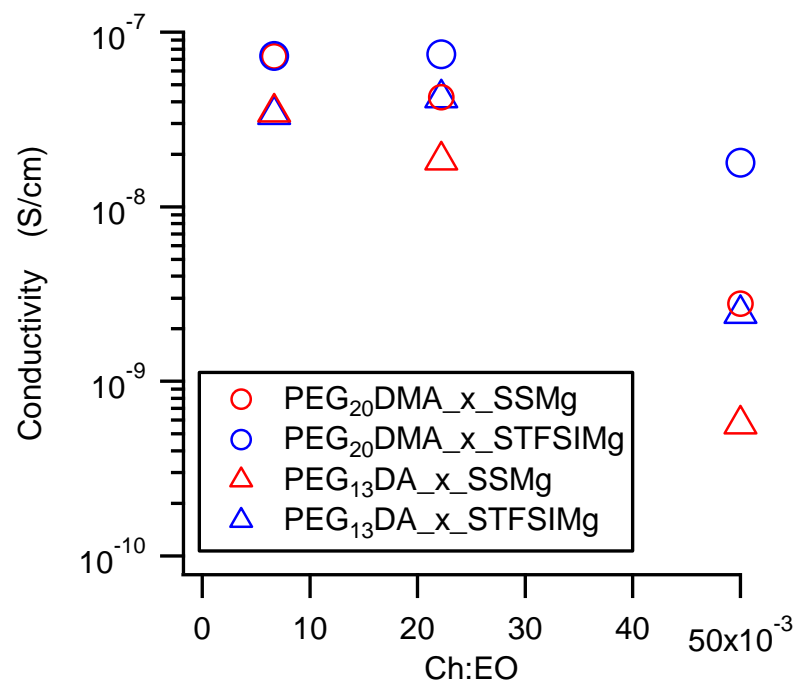

Figure 5. DC conductivity of THF swelled ionomers of varying crosslinker length, anion chemistry, and $\mathrm{Ch}: \mathrm{EO}$. 
Conductivity decreases as the effective pore size decreases. As either a result of crosslinker length or aggregation, the increased steric hindrance inhibits transport of solvated cation complexes. As the Ch:EO increases, differences in conductivity due to varying anion dissociability become noticeable, especially in the highest Ch:EO compositions where the SS samples are highly aggregated and the STFSI films less so.

To verify suitable conductivity for full cell operation, a select set of films are swelled in two different Mg-S compatible electrolyte systems, with the results presented in Figure 6.

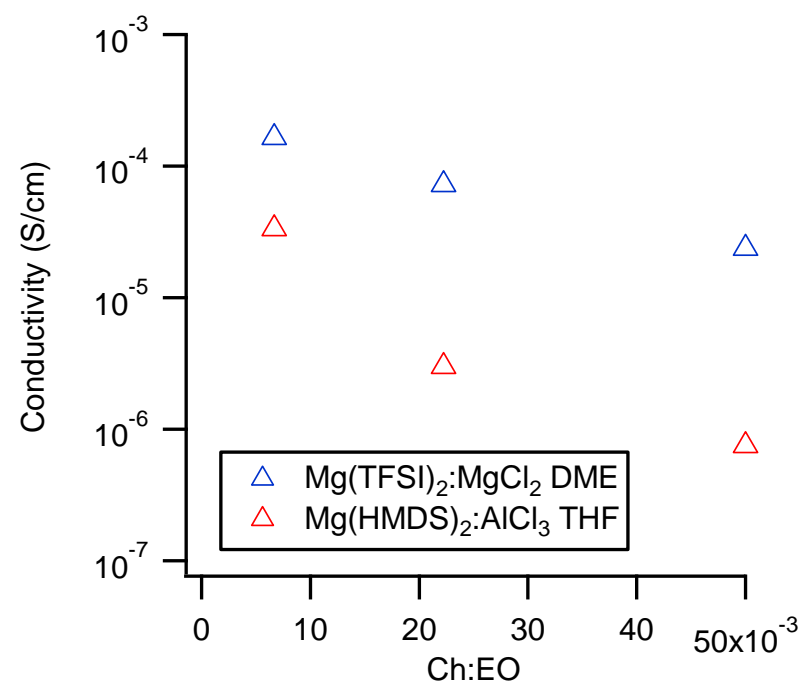

Figure 6. Conductivity of $\mathrm{PEG}_{13} \mathrm{DA} \_\mathrm{x} \_\mathrm{STFSIMg}$ films swelled with two electrolytes relevant for $\mathrm{Mg}$-S batteries.

In the ionomer films, the bulkier HMDS-containing complexes make the THF based electrolyte more than an order of magnitude less conductive than the DME electrolyte, even though the liquid electrolytes themselves are of comparable conductivity $(15 \mathrm{mS} / \mathrm{cm}$ and $4.3 \mathrm{mS} / \mathrm{cm}$ for the DME and THF based electrolytes, respectively). The conductivity of the DME electrolyte swelled samples, except for the highest $\mathrm{Ch}: \mathrm{EO}$, meet the accepted bare minimum of conductivity for practical use, $1 * 10^{-4} \mathrm{~S} / \mathrm{cm}$. Although both electrolytes are eventually used in full $\mathrm{Mg}-\mathrm{S}$ cells, cells with the THF based electrolyte are not fully functioning due to the inherent low conductivity.

\section{Magnesium Polysulfide Exclusion}

The effect of crosslinker length, anion chemistry, and Ch:EO ratio on the ability of a given film to exclude MgPS is examined with the use of an H-style diffusion cell, as shown in Figure 7. Figure 8 displays the UV/Vis background-subtracted absorption spectra for solutions collected from $\mathrm{H}$-cells run with various ionomer films, where here the background is taken to be the pristine electrolyte solution. The observed negative absorbance is elaborated upon in the SI, but briefly is a result of depletion of salts relative to the reference cuvette solution combined with low MgPS crossover. 


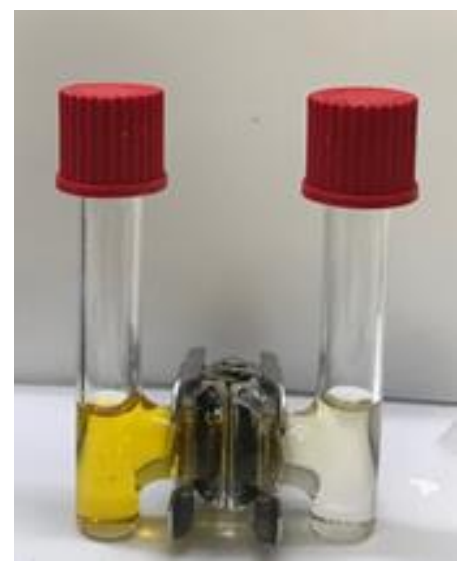

Figure 7. H-Style diffusion cell containing MgPS in THF based electrolyte on the left hand side, the same electrolyte without added sulfur on the right hand side, and the film to be tested in between. Pictured is the $\mathrm{H}$-cell containing a $\mathrm{PEG}_{20} \mathrm{DMA}$ film two hours after assembly.

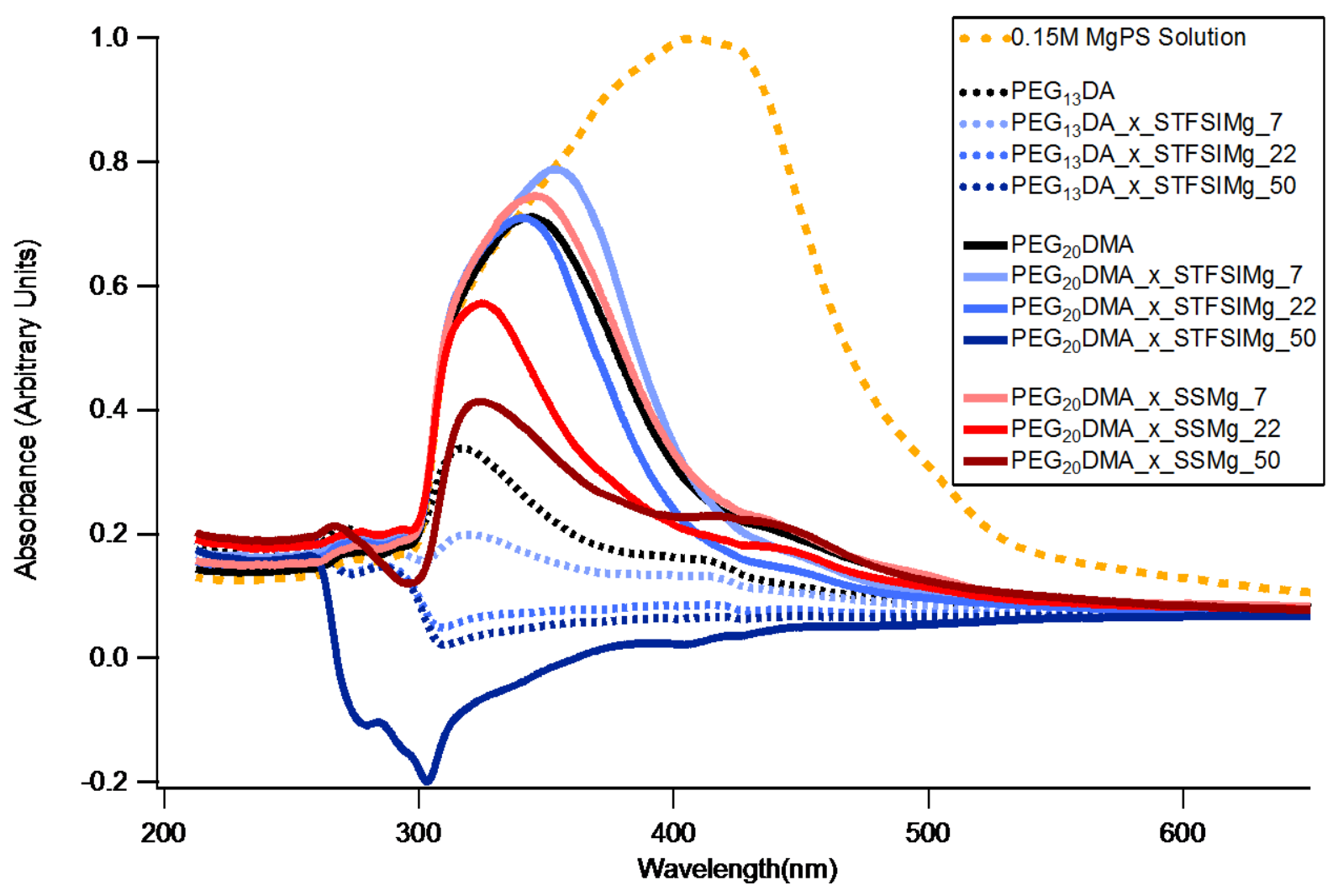

Figure 8. UV-VIS absorption spectra of polysulfide crossover solutions for $\mathrm{PEG}_{20} \mathrm{DMA}$ and $\mathrm{PEG}_{13} \mathrm{DA}$ films of varying Ch:EO and anion chemistry.

Total polysulfide crossover clearly decreases with shorter crosslinker lengths and ionomer aggregation. Although the exact speciation of the polysulfides in solution is not known, a decrease in the wavelength of maximum absorbance corresponds to a lower chain length 
polysulfide population (further discussion on this point in the SI Figure S5). Observation of the predominant crossover of shorter chain polysulfides in the case of aggregated and/or short crosslinker films is direct evidence that such films have smaller effective pore sizes. Comparing the PEG $_{20}$ DMA_x_SSMg_22 to PEG $_{20}$ DMA_x_STFSIMg_22, the former excludes MgPS to a greater degree due to the onset of ionic aggregation in the film as seen in the SAXS. Comparing $\mathrm{PEG}_{20}$ DMA_x_SSMg_50 and $\mathrm{PEG}_{20} \mathrm{DMA} \mathrm{x}$ _STFSIMg_50, the striking difference in absorbance is due to ion pair dissociation. Both samples are aggregated leading to physical restriction of MgPS, however PEG $_{20}$ DMA_x_STFSIMg_50 has a greater degree of ion pair dissociation, which offers additional MgPS restriction via electrostatic rejection.

Concerning the electrostatic rejection of polysulfides, the effective pore size of the material must be reasonably comparable (certainly within an order of magnitude) to the Debye screening length to have any effect. This explains the apparent contradictory effect of ionic units on the restriction capability of non-aggregated $\mathrm{PEG}_{13} \mathrm{DA}$ and $\mathrm{PEG}_{20} \mathrm{DA}$ films. In the case of the $\mathrm{PEG}_{20} \mathrm{DMA}$ films, the effective pore size must be large enough that the charge on a tethered anion can be screened with ample space left in the pore for a polysulfide anion to diffuse unhindered. Hence, substituting PEG chains for ineffective ionic units results in the observed greater polysulfide crossover. In contrast, when the pore size is small enough (all $\mathrm{PEG}_{13} \mathrm{DA}$ and $\mathrm{PEG}_{20}$ DMA_x_STFSIMg_50 films) electrostatic repulsion of polysulfide anions is observed.

The PEG $_{13}$ DA_x_STFSIMg compositions display a highly varied response to the MgPS solution, as can be seen by the films exposed to the H-cell solution pictured in Figure 9. As the Ch:EO increases, the mechanism of polysulfide crossover restriction changes, from that of absorptive trapping (pure $\mathrm{PEG}_{13} \mathrm{DA}$ ), to a degree of electrostatic rejection $\left(\mathrm{PEG}_{13} \mathrm{DA}\right.$ _ $\mathrm{x}$ _STFSIMg_7/22), to a combination of electrostatic and small pore size rejection $\left(\mathrm{PEG}_{13} \mathrm{DA}_{-} \mathrm{x} \_\mathrm{STFSIMg}\right.$ 50).

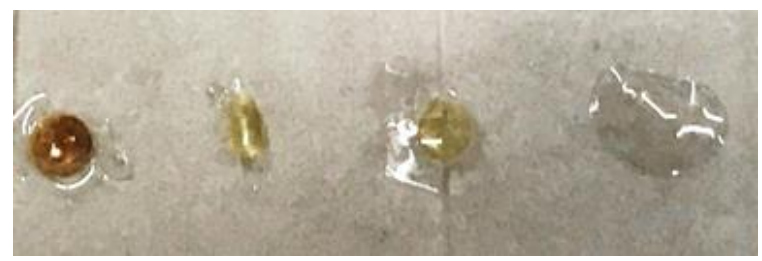

Figure 9. $\mathrm{PEG}_{13} \mathrm{DA}$ films recovered from diffusion cell experiments, from left to right $\mathrm{Ch}: \mathrm{EO}$ is $0,7,22$, and 50 .

\section{Mg-S Cell Cycling}

A series of Mg-S cells using the PEG $_{13}$ DA_x_STFSIMg films of varying Ch:EO as separators are assembled and cycled to study the impact on cell performance. Two electrolytes are studied, $\mathrm{Mg}(\mathrm{HMDS})_{2}: \mathrm{AlCl}_{3}$ in THF and $\mathrm{Mg}(\mathrm{TFSI})_{2}: \mathrm{MgCl}_{2}$ in DME. The potential curves as a function of capacity are presented in Figure 10 for $\mathrm{Mg}-\mathrm{S}$ cells employing the DME based electrolyte. Cells with the THF based electrolyte had poor initial discharge capacity and essentially non-existent charging capacity, with data shown in Figures S5 and S6 in the SI. 


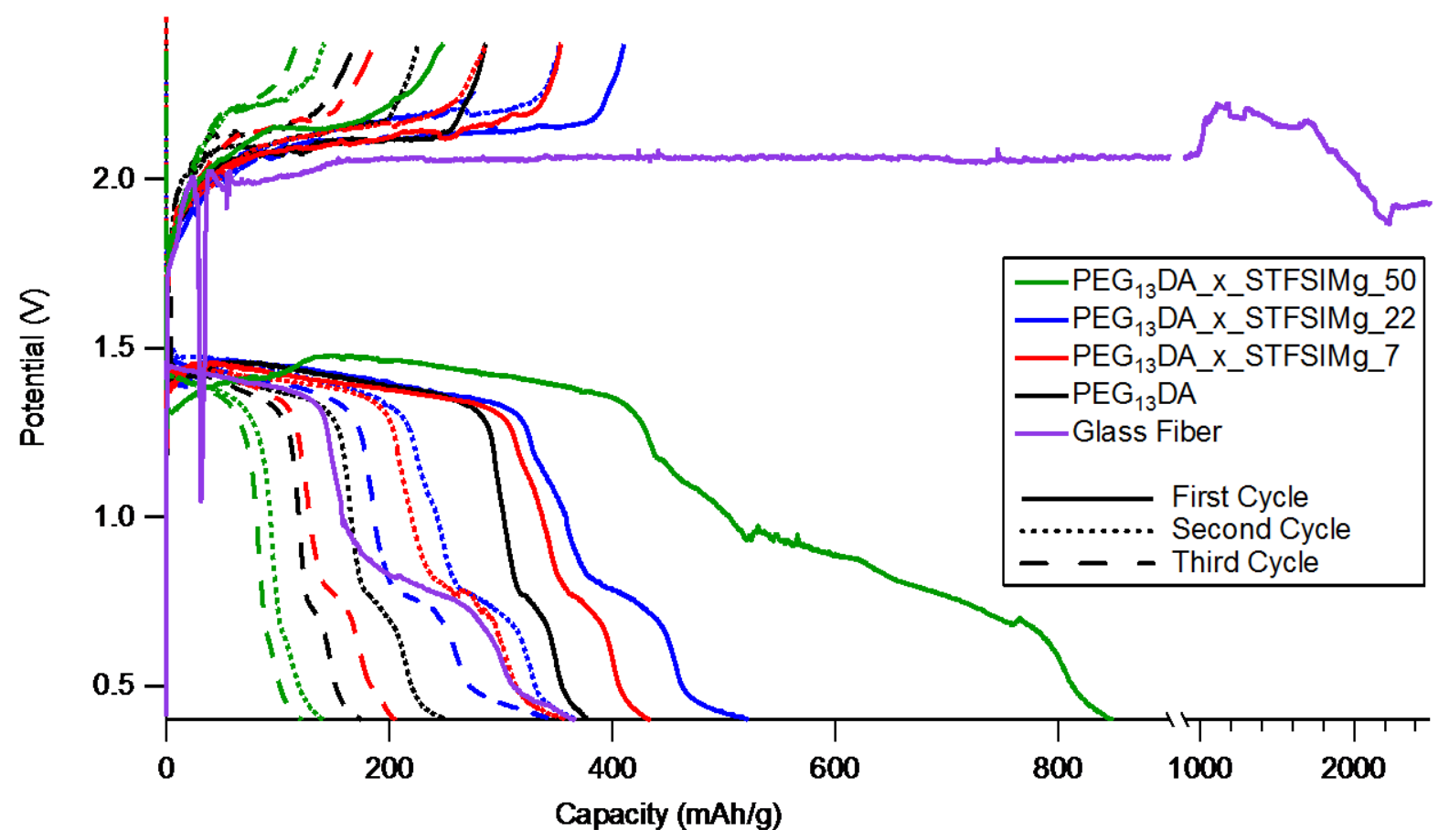

Figure 10. Discharge/charge potential curves for $\mathrm{Mg}$-S cells with varying separator material.

The initial discharge capacity appears highly correlated to the polysulfide rejecting capability of the separator used. When polysulfides are unable to diffuse away from reduction sites on the cathode, the active material utilization and hence discharge capacity are enhanced. The charging capacity also follows the same trend, with two exceptions: the glass fiber and the PEG $_{13}$ DA_x_STFSIMg_50 separators.

Cells with glass fiber separators are not able to charge to a preset cutoff potential, instead suffering continual "charging" at a given potential $\sim 2 \mathrm{~V}$ followed by eventual fluctuations in potential. The continual charging indicates such cells suffer from a serious polysulfide shuttle effect in which the reduction and oxidation of polysulfides is balanced at each electrode, thereby maintaining a constant potential. The simple fact that all the polymer separator cells are able to reach a designated cutoff potential indicates that they are capable of mitigating the shuttle effect to some extent.

Regarding the PEG $_{13}$ DA_x_STFSIMg_50 cell, the charging capacity is markedly lower than the other $\mathrm{PEG}_{13} \mathrm{DA}$ cells. This is hypothesized to be due to the low ionic conductivity of this film, which results in premature termination of charging. This demonstrates that for practical application, the best performing ionomer balances the ability to restrict MgPS but also conduct the active cation species.

The discharge curve of each cell contains two distinct plateaus, $\sim 1.4 \mathrm{~V}$ and $0.8 \mathrm{~V}$, with some cells exhibiting a third plateau near the discharge cutoff potential. The composition of the separator appears to not only impact the total discharge capacity, but also the capacity of each plateau. The capacity of the second plateau is inversely related to the MgPS absorptive capability of the 
separator, being highest for separators that do not absorb MgPS such as PEG $_{13} \mathrm{DA} \_\mathrm{x}-$ STFSIMg_50 and glass fiber. As these non-absorptive separators allow for a higher accessible concentration of MgPS, the second plateau is therefore assigned to the reduction of higher order MgPS to lower order MgPS. The origin of the third plateau is unknown at this time and requires further investigation.

Although the issue of capacity fading upon cycling is not completely mitigated, films that balance MgPS restriction and cationic conductivity see improved capacity retention. After three cycles, the capacity retention of the PEG $_{13}$ DA_x_STFSIMg_22, PEG 13 DA_x_STFSIMg_7, and pure $\mathrm{PEG}_{13} \mathrm{DA}$ cells are $66.9 \%, 47.2 \%$, and $46.1 \%$ of initial, respectively. Mechanisms of capacity fade are likely to include the poor kinetics associated with upgrading final discharge product $\mathrm{MgS}$ during the charge cycle and loss of active material due to absorption into the separator. Future studies should focus on the usage of materials as thin layered cathode coatings as opposed to bulk scale separators. Thin layer coatings will not absorb as much active material leading to better life cycle, and will widen the range of applicable materials by loosening the conductivity requirements.

\section{Conclusions}

A series of crosslinked ionomer films consisting of varying chain lengths, anion chemistry, and $\mathrm{Ch}: \mathrm{EO}$ were synthesized. These materials were further characterized in terms of structure, conductivity, ability to repel MgPS, and performance enhancement of full $\mathrm{Mg}-\mathrm{S}$ cells employing the ionomers as separators. It was confirmed that tethered anions could electrostatically repel negatively charged polysulfide anions. Furthermore, it was determined that anion chemistry, in particular anion dissociability, plays a large part in controlling the ionomer structure and transport properties by modulating ionic aggregation within the film. Relative to standard commercial glass fiber separators, the ionomer separators enhanced the performance of $\mathrm{Mg}-\mathrm{S}$ cells in terms of discharge capacity and effectively suppressed the polysulfide shuttle effect. Although further work is required to improve cation transport and capacity retention, the elucidation of structure-composition-property relationships can hopefully guide the engineering of better materials for $\mathrm{Mg}-\mathrm{S}$ and other metal-sulfur batteries.

\section{Associated Content}

Supporting information

Supplementary SAXS spectra, conductivity measurements, UV/VIS experiments, Mg-S cell cycling.

\section{Author Information Corresponding Author}

*E-mail: Jennifer.L.Schaefer.43@nd.edu; Phone: (574)-631-5114

\section{ORCID}

Jennifer L. Schaefer: 0000-0003-4293-6328

Notes

The authors declare no competing financial interest. 


\section{Acknowledgements}

We thank Dr. Xiaobing Zuo from Argonne National Lab for assistance in collecting SAXS spectra, Dr. Ian Lightcap and the Notre Dame Materials Characterization Facility for UV/VIS instrumentation, Jon Loftus and the Notre Dame Center for Environmental Science and Technology for ICP-OES and ion chromatography instrumentation. This research used resources of the Advanced Photon Source, a U.S. Department of Energy (DOE) Office of Science User Facility operated for the DOE Office of Science by Argonne National Laboratory under Contract No. DE-AC02-06CH11357. Hunter O. Ford acknowledges financial support from The Society of Arthur J. Schmitt Fellows. The authors gratefully acknowledge funding from the National Science Foundation via award number CBET-1706370.

\section{References}

(1) Kim, H. S.; Arthur, T. S.; Allred, G. D.; Zajicek, J.; Newman, J. G.; Rodnyansky, A. E.; Oliver, A. G.; Boggess, W. C.; Muldoon, J. Structure and Compatibility of a Magnesium Electrolyte with a Sulphur Cathode. Nat. Commun. 2011, 2 (1).

(2) Vinayan, B. P.; Zhao-Karger, Z.; Diemant, T.; Chakravadhanula, V. S. K.; Schwarzburger, N. I.; Cambaz, M. A.; Behm, R. J.; Kübel, C.; Fichtner, M. Performance Study of MagnesiumSulfur Battery Using a Graphene Based Sulfur Composite Cathode Electrode and a NonNucleophilic Mg Electrolyte. Nanoscale 2016, 8 (6), 3296-3306.

(3) Zhao-Karger, Z.; Zhao, X.; Wang, D.; Diemant, T.; Behm, R. J.; Fichtner, M. Performance Improvement of Magnesium Sulfur Batteries with Modified Non-Nucleophilic Electrolytes. Adv. Energy Mater. 2015, 5 (3), 1401155.

(4) Yu, X.; Manthiram, A. Performance Enhancement and Mechanistic Studies of Magnesium-Sulfur Cells with an Advanced Cathode Structure. ACS Energy Lett. 2016, 1 (2), 431-437.

(5) Du, H.; Zhang, Z.; He, J.; Cui, Z.; Chai, J.; Ma, J.; Yang, Z.; Huang, C.; Cui, G. A Delicately Designed Sulfide Graphdiyne Compatible Cathode for High-Performance Lithium/Magnesium-Sulfur Batteries. Small 2017, 13 (44), 1702277.

(6) Gao, T.; Hou, S.; Wang, F.; Ma, Z.; Li, X.; Xu, K.; Wang, C. Reversible SO/MgSxRedox Chemistry in a MgTFSI2/MgCl2/DME Electrolyte for Rechargeable Mg/S Batteries. Angew. Chemie - Int. Ed. 2017, 56 (43), 13526-13530.

(7) Fan, X.; Sun, W.; Meng, F.; Xing, A.; Liu, J. Advanced Chemical Strategies for LithiumSulfur Batteries: A Review. Green Energy Environ. 2017, 3 (1), 2-19.

(8) Manthiram, A.; Fu, Y.; Chung, S. H.; Zu, C.; Su, Y. S. Rechargeable Lithium-Sulfur Batteries. Chemical Reviews. 2014, 114 (23), 11751-11787.

(9) Jin, Z.; Xie, K.; Hong, X. Electrochemical Performance of Lithium/Sulfur Batteries Using Perfluorinated Ionomer Electrolyte with Lithium Sulfonyl Dicyanomethide Functional Groups as Functional Separator. RSC Adv. 2013, 3 (23), 8889-8898. 
(10) Jin, Z.; Xie, K.; Hong, X.; Hu, Z.; Liu, X. Application of Lithiated Nafion Ionomer Film as Functional Separator for Lithium Sulfur Cells. J. Power Sources 2012, 218, 163-167.

(11) Ma, L.; Nath, P.; Tu, Z.; Tikekar, M.; Archer, L. A. Highly Conductive, Sulfonated, UV-CrossLinked Separators for Li-S Batteries. Chem. Mater. 2016, 28 (14), 5147-5154.

(12) Ma, G.; Wen, Z.; Jin, J.; Lu, Y.; Wu, X.; Wu, M.; Chen, C. Hollow Polyaniline Sphere@sulfur Composites for Prolonged Cycling Stability of Lithium-Sulfur Batteries. J. Mater. Chem. A 2014, 2 (27), 10350-10354.

(13) Hyun, J.; Lee, P.; Jung, M.; Ishihara, T. A Simple Preparation of Polyaniline-Coated Sulfur Composites for Use as Cathodes in Li-S Batteries. Electrochemistry 2016, 84 (11), 836841.

(14) Li, W.; Zhang, Q.; Zheng, G.; Seh, Z. W.; Yao, H.; Cui, Y. Understanding the Role of Different Conductive Polymers in Improving the Nanostructured Sulfur Cathode Performance. Nano Lett. 2013, 13 (11), 5534-5540.

(15) Meziane, R.; Bonnet, J. P.; Courty, M.; Djellab, K.; Armand, M. Single-lon Polymer Electrolytes Based on a Delocalized Polyanion for Lithium Batteries. Electrochimica Acta; 2011, 57 (1), 14-19.

(16) Liao, C.; Sa, N.; Key, B.; Burrell, A. K.; Cheng, L.; Curtiss, L. A.; Vaughey, J. T.; Woo, J. J.; Hu, L.; Pan, B.; et al. The Unexpected Discovery of the $\mathrm{Mg}(\mathrm{HMDS})_{2}-\mathrm{MgCl}_{2}$ Complex as a Magnesium Electrolyte for Rechargeable Magnesium Batteries. J. Mater. Chem. A 2015, 3 (11), 6082-6087.

(17) Zhao-Karger, Z.; Zhao, X.; Fuhr, O.; Fichtner, M. Bisamide Based Non-Nucleophilic Electrolytes for Rechargeable Magnesium Batteries. RSC Adv. 2013, 3 (37), 16330-16335.

(18) Wang, J. H. H.; Yang, C. H. C.; Masser, H.; Shiau, H. S.; O’Reilly, M. V.; Winey, K. I.; Runt, J.; Painter, P. C.; Colby, R. H. Ion States and Transport in Styrenesulfonate Methacrylic PEO9 Random Copolymer Ionomers. Macromolecules 2015, 48 (19), 7273-7285.

(19) De Molina, P. M.; Lad, S.; Helgeson, M. E. Heterogeneity and Its Influence on the Properties of Difunctional Poly(Ethylene Glycol) Hydrogels: Structure and Mechanics. Macromolecules 2015, 48(15), 5402-5411.

(20) Waters, D. J.; Engberg, K.; Parke-Houben, R.; Hartmann, L.; Ta, C. N.; Toney, M. F.; Frank, C. W. Morphology of Photopolymerized End-Linked Poly(Ethylene Glycol) Hydrogels by Small-Angle X-Ray Scattering. Macromolecules 2010, 43 (16), 6861-6870.

(21) Diao, Y.; Helgeson, M. E.; Siam, Z. A.; Doyle, P. S.; Myerson, A. S.; Hatton, T. A.; Trout, B. L. Nucleation under Soft Confinement: Role of Polymer-Solute Interactions. Cryst. Growth Des. 2012, 12 (1), 508-517. 
(22) Förster, S.; Timmann, A.; Schellbach, C.; Frömsdorf, A.; Kornowski, A.; Weller, H.; Roth, S. V.; Lindner, P. Order Causes Secondary Bragg Peaks in Soft Materials. Nat. Mater. 2007, 6 (11), 888-893.

(23) Seitz, M. E.; Chan, C. D.; Opper, K. L.; Baughman, T. W.; Wagener, K. B.; Winey, K. I. Nanoscale Morphology in Precisely Sequenced Poly(Ethylene- Co -Acrylic Acid) Zinc Ionomers. J. Am. Chem. Soc. 2010, 132 (23), 8165-8174.

(24) Elmore, C. T.; Seidler, M. E.; Ford, H. O.; Merrill, L. C.; Upadhyay, S. P.; Schneider, W. F.; Schaefer, J. L. Single-Ion Conducting Polymer Electrolytes for Post-Lithium Ion Batteries. Batteries 2018, 4 (2), 28.

(25) Tant, M.; Mauritz, K.; Wilkes, G. Ionomers: Synthesis, Structure, Properties and Applications; Blackie Academic and Professional: New York, 2012.

(26) Hall, L. M.; Seitz, M. E.; Winey, K. I.; Opper, K. L.; Wagener, K. B.; Stevens, M. J.; Frischknecht, A. L. Ionic Aggregate Structure in lonomer Melts: Effect of Molecular Architecture on Aggregates and the Ionomer Peak. J. Am. Chem. Soc. 2012, 134 (1), 574587.

\section{Supporting Information}

Crosslinked ionomer gel separators for polysulfide shuttle mitigation in magnesium-sulfur batteries: Elucidation of structure-property relationships

Hunter O. Ford, Laura C. Merrill, Peng He, Sunil P. Upadhyay, Jennifer L. Schaefer*

Department of Chemical and Biomolecular Engineering, University of Notre Dame, Notre Dame, IN 46556, USA

\section{Relationship between aggregation and ion dissociation}

To illustrate that the degree of aggregation is less with greater ion dissociation, the films are swelled in DMSO and studied in terms of conductivity and with SAXS. As a high dielectric constant solvent, DMSO is capable of dissociating nearly all ion pairs over the Ch:EO studied, as can be seen in the conductivity plot in Figure S1. 


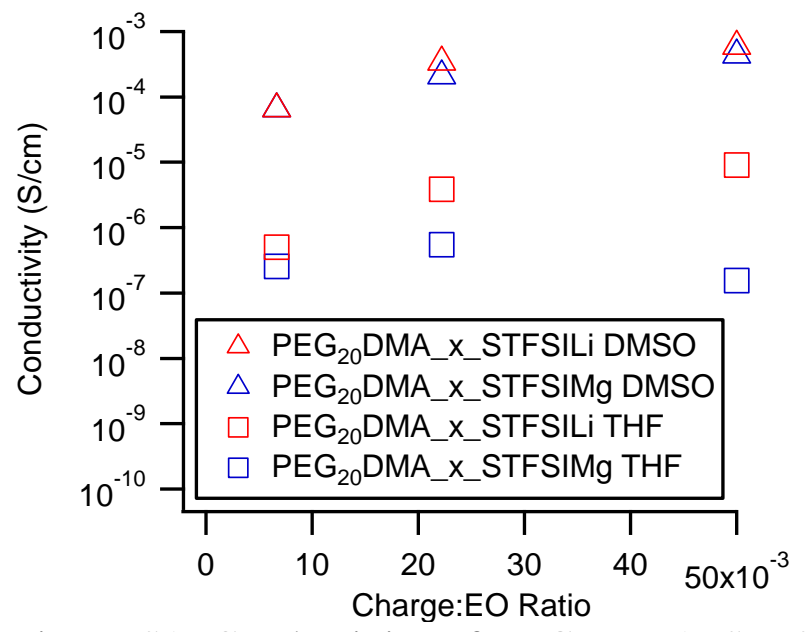

Figure S1. Conductivity of $\mathrm{PEG}_{20}$ DMA_STFSI films of varying cation chemistry and Ch:EO swelled in different solvents.

In Figure S1, as the Ch:EO rises for the THF swelled samples a clear difference between cation is noticeable, with $\mathrm{Li}$ samples being more conductive than $\mathrm{Mg}$. As a monovalent cation, $\mathrm{Li}$ does not induce aggregation at these $\mathrm{Ch}: \mathrm{EO}$ and is all-around more mobile. In DMSO, the essentially identical conductivity of $\mathrm{Mg}$ and $\mathrm{Li}$ samples and the increasing conductivity with increasing $\mathrm{Ch}: \mathrm{EO}$ indicates DMSO completely dissociates all ionic groups in this $\mathrm{Ch}: \mathrm{EO}$ regime.

As seen in Figure S2, under the condition of full ion pair dissociation due to DMSO swelling, the position of the shoulder does not shift with increasing $\mathrm{Ch}: \mathrm{EO}$, indicating no change in length scale between scattering structures. The intensity of the shoulder increases because more SLD contrasting ionic units are present at the acrylate backbone sites. Indicated by the lack of change in characteristic length scale, the samples do not experience aggregation with increasing Ch:EO. Hence, aggregation is lessened with a greater degree of dissociated ionic units. 


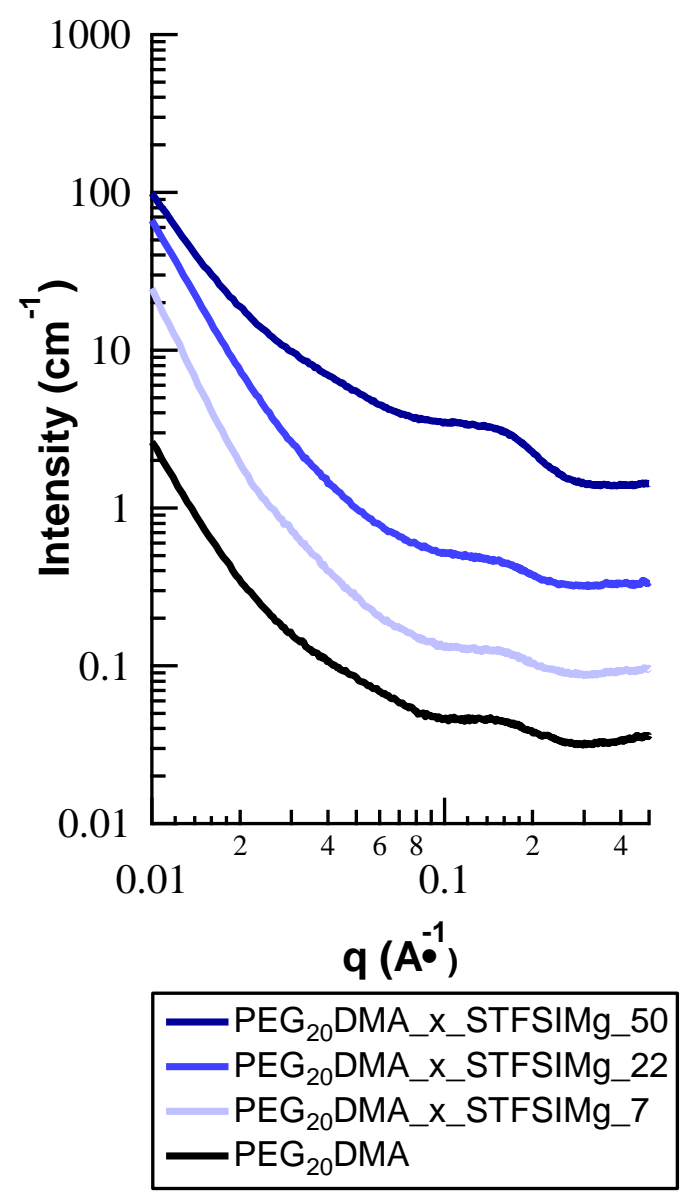

Figure S2. SAXS spectra of ionomer films swelled in DMSO. Spectra are shifted vertically for clarity.

\section{UV/VIS Studies - Negative absorbance and MgPS chain length}

At first glance, the negative absorbance of the solutions in Figure 8 produced by the highest Ch:EO films seems non-physical. Further investigation revealed an interesting salt transport phenomenon responsible for the observed absorbance. The use of ICP-OES, ${ }^{1} \mathrm{H}$ NMR, and Clion chromatography showed a reduction in concentration of magnesium, chloride, and hexamethyldisilazide related species in the side of the h-cell that is loaded with neat electrolyte. The degree of reduction in salt concentration appears to be primarily a function of the effective pore size, as can be seen in Table S1. The salts in the neat electrolyte side of the cell are transported into and through the ionomer into the side of the cell with the MgPS solution, presumably to a concentration gradient established by the reaction that forms the MgPS. $\mathrm{PEG}_{20}$ DMA and $\mathrm{PEG}_{20}$ DMA_x_STFSIMg_7 experience a high degree of MgPS crossover, which is why the $\mathrm{Mg}$ concentration in the solutions from these films does not seem to follow the pore size trend.

\begin{tabular}{lll}
\hline H-cell diffusion solution & $\begin{array}{l}\text { Percent } \mathrm{Mg}^{2+} \\
\text { relative to pristine }\end{array}$ & $\begin{array}{l}\text { Percent } \mathrm{Cl}^{-} \\
\text {relative to pristine }\end{array}$ \\
\hline
\end{tabular}




\begin{tabular}{lccc}
\hline & electrolyte & & electrolyte \\
\hline PEG20DMA & & 88.0 & 50.1 \\
PEG20DMA_x_STFSIMg_7 & 76.9 & 74.3 \\
PEG20DMA_x_STFSIMg_22 & 69.5 & 79.6 \\
PEG20DMA_x_STFSIMg_50 & 78.7 & 76.0 \\
PEG13DA & 71.1 & 62.8 \\
PEG13DA_x_STFSIMg_7 & 72.7 & 77.1 \\
PEG13DA_x_STFSIMg_22 & 68.8 & 81.8 \\
PEG13DA_x_STFSIMg_50 & 85.2 & 78.8 \\
\hline
\end{tabular}

Table S1. Percent of $\mathrm{Mg}^{2+}$ and $\mathrm{Cl}^{-}$in h-cell solutions relative to the as-prepared electrolyte. $\mathrm{Mg}^{2+}$ determined via ICP-OES, $\mathrm{Cl}^{-}$determined via ion chromatography.

A comparison of ${ }^{1} \mathrm{H}$ NMR integration values for HMDS species from $\mathrm{H}$-cell solutions and pure $\operatorname{Mg}(\text { HMDS })_{2}$ in THF show a reduction in total HMDS species concentration $(\delta 0.19)$, being integrated at $1.52,1.36$, and 1.81 for PEG $_{20}$ DMA, PEG 20 DMA_x_STFSIMg_50, and pristine solutions respectively. NMR samples were prepared by dissolving equal volumes of $\mathrm{h}$-cell solution or $\mathrm{Mg}(\mathrm{HMDS})_{2}$ THF solution in deuterated benzene. The $\mathrm{Mg}(\mathrm{HMDS})_{2}$ THF solution is made to the same concentration as the neat electrolyte. This allows for comparison of relative concentration of HMDS species via integration.

The concentration of HMDS in the h-cell solutions is less than the concentration of HMDS in the prepared electrolyte. As the reference cuvette contains the same electrolyte that is loaded into the diffusion cells, the reduced concentration of HMDS species in the diffusion solution leads to the observed negative absorbance. HMDS absorbs in the same wavelength region as MgPS (Figure S3), so the negative absorbance is only observed when the MgPS concentration is sufficiently low, i.e. the MgPS absorbance does not obscure the reduced HMDS concentration. In other words, in this particular setup negative absorbance indicates that MgPS transport is severely limited in a given film while transport of HMDS containing complexes such as [(HMDS) $\left.\mathrm{MgCl}_{2}\right]^{-}$ , (HMDS) $\mathrm{Mg}^{+}$, (HMDS) $\mathrm{MgCl}$, etc. is allowed. In light of the demonstrated electrostatic repulsion of anions, likely neutral or positive species are being transported across the films.

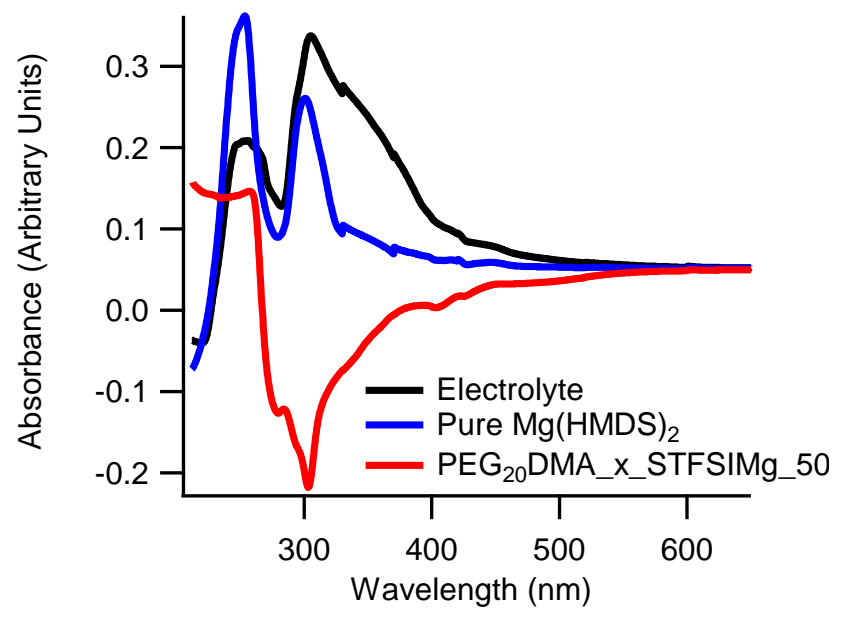


Figure $\mathrm{S} 3$. Absorbance patterns of $\mathrm{Mg}(\mathrm{HMDS})_{2}: \mathrm{MgCl}_{2}$ electrolyte and $\mathrm{Mg}(\mathrm{HMDS})_{2}$ in $\mathrm{THF}$. Note the spectra for PEG ${ }_{20}$ DMA_x_STFSIMg_50 is the near perfect inverse of the electrolyte solution. The absorbance of the electrolyte itself, in particular HMDS species, overlaps with MgPS absorbance $(300-400 \mathrm{~nm})$.

\section{MgPS Chain length}

It was observed that sulfur could be added to the $\mathrm{Mg}(\mathrm{HMDS})_{2}: \mathrm{MgCl}_{2}$ in THF electrolyte and fully dissolved at concentrations far exceeding the solubility limit of sulfur in pure THF (up to $1.5 \mathrm{M}$ in the electrolyte). It is therefore inferred that as more sulfur is added to the MgPS solution, which contains a fixed concentration of magnesium, the sulfur dissolves because it undergoes ring opening and addition to the polysulfide anion chains already in solution. Therefore, as the amount of sulfur added increases, the average length of the polysulfide chains in solution increases. This is confirmed with the use of the ionomer separators in an h-cell. Concentrations of $\sim 0.5 \mathrm{M}$ sulfur and above produce sulfur chain lengths that do not cross over any of the studied films, indicating the PS chain length exceeds the pore size of the networks.

The wavelength of maximum absorbance shifts to higher values as the chain length of the sulfur increases, as can be seen in Figure S4. This phenomenon allows for commenting on the relative differences in effective pore size of the ionomer materials in the main text.

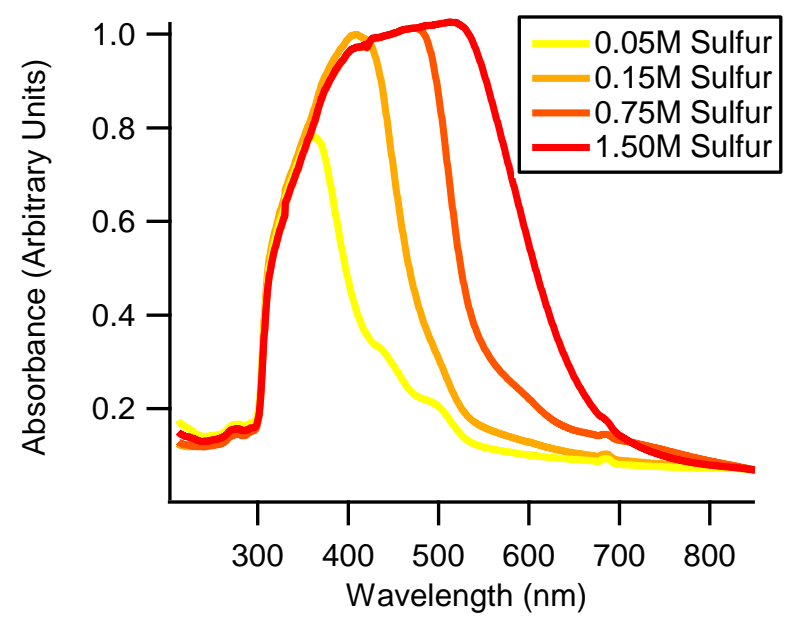

Figure S4. Absorbance patterns of $\mathrm{Mg}(\mathrm{HMDS})_{2}: \mathrm{MgCl}_{2}$ : sulfur solutions of various concentrations.

\section{Mg-S Cells with $\mathrm{Mg}(\mathrm{HMDS})_{2}: \mathrm{AlCl}_{3}$ THF based electrolyte}

$\mathrm{Mg}-\mathrm{S}$ cells employing the $\mathrm{Mg}(\mathrm{HMDS})_{2}: \mathrm{AlCl}_{3}$ THF based electrolyte exhibit poor performance, especially in terms of charging. From the conductivity discussion in the main text, it is known that the films swelled in this electrolyte are sufficiently non-conductive, to the point where the resistance across the film clearly impacts the performance of the cell. As seen in Figure S5, initial discharge capacity is higher when the separator pore size is higher, being greatest for the macro-porous glass fiber separator, as the bulky complexes in this electrolyte are less sterically hindered. Note the GF separator charging behavior is similar to the infinite charge seen in the 
$\mathrm{Mg}(\mathrm{TFSI})_{2}: \mathrm{MgCl}_{2}$ DME electrolyte GF cell, while the ionomer films have very low charging capacity. Capacity fading is almost instantaneous as a result of very low charging capacity, as can be seen in Figure S6.

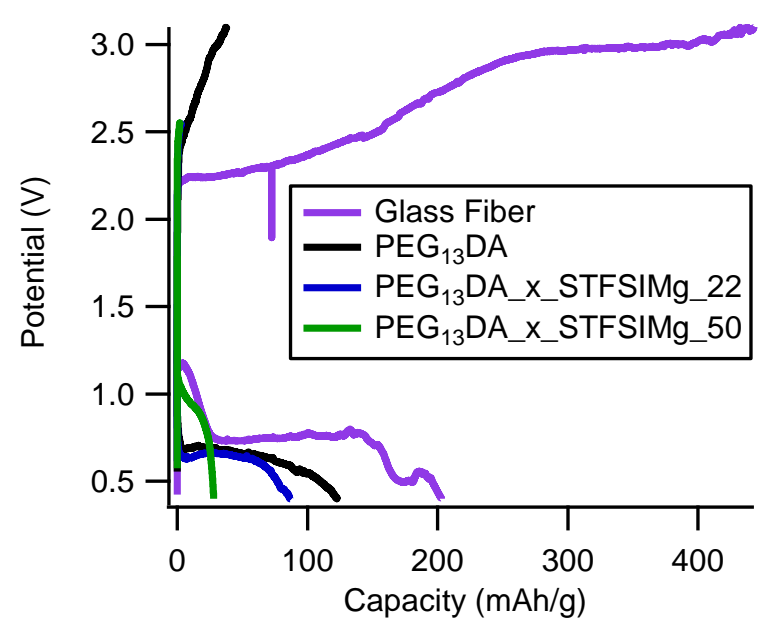

Figure S5. First cycle charge/discharge curves of Mg-S cells with $\mathrm{Mg}(\mathrm{HMDS})_{2}: \mathrm{AlCl}_{3}$ in THF electrolyte, with varying separators.

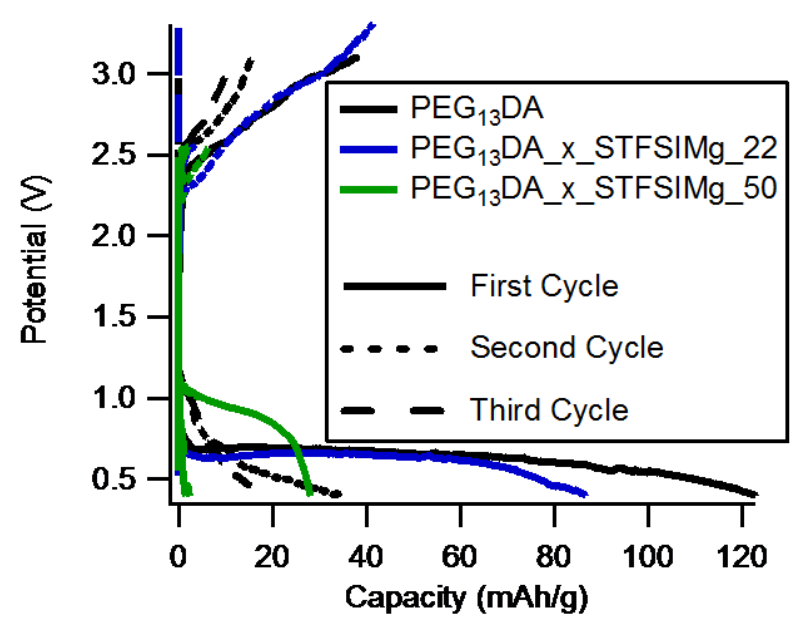

Figure S6. First three cycles of Mg-S cells with $\mathrm{Mg}(\mathrm{HMDS})_{2}: \mathrm{AlCl}_{3}$ in THF electrolyte, with ionomer separators. 